\title{
Federalismo republicano, anarquista e ameríndio: uma dupla torção ${ }^{1}$
}

\author{
Guilherme Lavinas Jardim Falleiros \\ Universidade de São Paulo
}

Resumo: Este é um experimento de aplicação do método de análise estrutural dos mitos ameríndios de Claude Lévi-Strauss e sua "fórmula canônica" na comparação de formas políticas republicanas, anarquistas e ameríndias, tomando como premissa a afirmação do autor de que "nada se assemelha mais ao pensamento mítico que a ideologia política". Considera-se que a "fórmula canônica" é um efeito de modos de pensar ameríndios, presentes na mitologia das Américas, na dialética sem termo lévi-straussiana. Assim recupera-se a relação entre mito e cosmopolítica do "dualismo em perpétuo desequilíbrio feito política", estudado por PerroneMoisés e Sztutman, comparada ao anarquismo em pesquisa pessoal recente, agora estendendo a comparação à tradição republicana, incluindo o federalismo das repúblicas norte-americana e brasileira e suas peculiares relações com as questões indígenas. Sugere-se que formas políticas ameríndias operam dupla torção sobre formas republicanas.

Palavras-chave: republicanismo, anarquismo, ameríndios, dupla torção.

\footnotetext{
${ }^{1}$ Este artigo apresenta correções, mudanças e acréscimos à comunicação apresentada à XII European Social Science History Conference, Belfast (Abril, 2018) cujo argumento serviu como base para a oficina "A case of the structural study of myth applied to politics", Loughborough University (Março, 2018), financiada pelo Santander Mobility Award, o que não teria sido possível sem o apoio da professora Ruth Kinna, a quem sou muito grato. Agradeço também ao colega André Drago pela sugestão de leitura da obra de J. G. A. Pocock num momento inicial da pesquisa que aqui culmina.
} 


\title{
Republican, Anarchist and Amerindian Federalism: a double twist
}

\begin{abstract}
This is an experiment in the application of the method of structural analysis of the Amerindian myths of Claude Lévi-Strauss and his "canonical formula" in the comparison of republican, anarchist, and Amerindian political forms, based on the author's assertion that "nothing resembles more to mythical thinking than political ideology. " The "canonical formula" is considered to be an effect of Amerindian modes of thought, present in the mythology of the Americas, in the dialectic without Levy-Straussian term. Thus the relationship between myth and cosmopolitics of the "dualism in perpetual political unbalance", studied by Perrone-Moisés and Sztutman, is recovered, compared to anarchism in recent personal research, now extending the comparison to the republican tradition, including the federalism of the northern republics American and Brazilian and its peculiar relations with indigenous issues. It is suggested that Amerindian political forms operate with double twist on republican forms.
\end{abstract}

Keywords: republicanism, anarchism, Amerindian, double twist.

\section{Federalismo republicano, anarquista y amerindio: una doble torsión}

\begin{abstract}
Resumen: Esta es una aplicación del método de análisis estructural experimental de los mitos amerindios de Claude Levi-Strauss y su "fórmula canónica" en las formas políticas de comparación republicana, anarquistas y amerindia, teniendo como premisa la afirmación del autor de que "nada es más como Al pensamiento mítico que a la ideología política ". La "fórmula canónica" se considera un efecto de los modos de pensamiento de los amerindios, presentes en la mitología de las Américas, en la dialéctica sin el término levy-straussiano. Así que recupera la relación entre el mito y cosmopolítica el "dualismo en desequilibrio perpetuo hizo política", estudiado por Perrone-Moisés y Sztutman en comparación con el anarquismo en la investigación personal reciente, ahora se extiende la comparación con la tradición republicana, incluyendo el federalismo de las repúblicas del norte Americano y brasileño y sus peculiaridades con las cuestiones indígenas. Se sugiere que las formas políticas amerindias operen con doble giro en las formas republicanas.
\end{abstract}

Palabras clave: republicanismo, anarquismo, amerindios, doble torsión. 
$\mathrm{F}$ lalar sobre política republicana pode parecer um desvio do fazer política entre coletivos ameríndios. Todavia, são os próprios coletivos indígenas que se mantém envolvidos na política republicana brasileira, tendo sua participação sido fundamental na última constituinte, o que pode ter ajudado a garantir o que o jurista Samuel Barbosa considera uma simetrização entre perspectiva indígena e o direito estatal na constituição federal de 1988 (informação verbal) ${ }^{2}$. Portanto, importa entender as diferenças e semelhanças "transformações" - entre os modos indígenas e não-indígenas, para compreender este envolvimento. Este artigo pretende dar subsídios para isto.

Em outros textos (FALLEIROS, 2015, 2016, 2017) argumentei que uma certa dialética ameríndia, tomada de uma perspectiva lévi-straussiana, lida com "perturbações" sobre a dialética serial consideradas por Pierre-Joseph Proudhon como elementos da realidade não previstos pela lógica abstrata. Assim, o que seriam perturbações nas analogias silogísticas decorrem, em casos ameríndios, do cruzamento de mais de uma perspectiva sobre a mesma relação que compõe uma série. Foi estudada a "série política", chamada por Proudhon de "dualismo político", tratando da relação de superioridade da "Liberdade" sobre a "Autoridade" na constituição de federações, e sua transformação ameríndia na forma do "dualismo em perpétuo desequilíbrio feito política" concebido no estudo de confederações indígenas por Beatriz Perrone-Moisés e Renato Sztutman, sob influência lévi-straussiana e clastriana. Agora alargo esta reflexão para formas políticas republicanas, com as quais as obras de Élisée Reclus e de Proudhon (cuja dialética teria influenciado Claude Lévi-Strauss) dialogam, tomando seus enunciados como função mediadora entre republicanos e ameríndios. Além dos enunciados do republicanismo clássico, do anarquismo e de formas ameríndias, articula-se a isto um quarto conjunto de enunciados, sobre federalismo republicano nas Américas, especialmente nos Estados Unidos da América e no Brasil. Assim, para esta comparação alargada, tomo como ferramenta a "fórmula canônica do mito" de Lévi-Strauss, desenvolvida para lidar com fronteiras e limiares.

Eduardo Viveiros de Castro faz algo semelhante ao extrapolar tal fórmula do mito à filosofia (ainda que sem explaná-la formalmente), argumentando que o "perspectivismo multinaturalista" ameríndio é uma transformação, por dupla torção, do multiculturalismo ocidental. "Ele assinala o cruzamento de um umbral ou limite, um limiar semiótico-histórico que é um limiar de tradutibilidade e de equivocidade; um limiar, justamente, de transformação perspectiva" (2015 [2009]: 69). José Antônio Kelly realizou esta explanação, extendendo a fórmula canônica ao perspectivismo multinaturalista (2010) e, com estes autores, enfatiza-se que limiares "semiótico-históricos" ou "culturais" podem ser melhor compreendidos como pontos de transformação perspectiva.

Imagino que o perspectivismo de Proudhon possa ser a primeira torção dessa dupla, mediando o "multiculturalista" e o "multinaturalista". Pois argumentei (FALLEIROS, 2016) que cosmopolíticas ameríndias têm relação transformacional com a dialética serial de Proudhon, trazendo perspectivas desviantes sobre a mesma relação. Daí, a "série política", afetada por outras perspectivas, transforma-se em outras séries, como a série de gênero e suas assimetrias recíprocas ou naquela que conecta guerra, jogo e festa - dialogando

2 Palestra "A questão indígena hoje” com Manuela Carneiro da Cunha, Livraria Tapera Taperá, São Paulo, 17 de Maio de 2017. 
com o par "festa e guerra” proposto por Perrone-Moisés (2015).

Em suma, olho para a política não-indígena através de uma fórmula influenciada pela razão indígena (Lévi-Strauss, 1975 [1955]; Almeida, 2009) para correlacionar enunciados da tradição republicana a ameríndios, mediados por enunciados de Proudhon e Élisée Reclus.

A seguir, apresento considerações a respeito da relação entre mito, história e política. Na seção subsequente aponto para relações entre republicanismo e anarquismo. Depois abordo elementos de formas políticas ameríndias que podem ser relacionados aos das formas anteriores. Finalmente, mostro hipóteses de uso da fórmula canônica nestes enunciados da "série política".

\section{Mito, história e política}

Apesar da fórmula canônica ter sido criada para lidar com mitologias ameríndias e suas lógicas peculiares, Lévi-Strauss foi o primeiro a utilizá-la fora de seu terreno original, aplicando-a a um famoso mito europeu, o de Édipo, tendo antes identificado uma equivalência entre mito e política num conhecido trecho de sua obra:

\footnotetext{
Nada se assemelha mais ao pensamento mítico que a ideologia política. Em nossas sociedades contemporâneas, talvez esta tenha se limitado a substituir aquele. Ora, o que faz o historiador quando evoca a Revolução Francesa? Ele se refere a uma seqüência de acontecimentos passados, cujas conseqüências longínquas se fazem, sem dúvida, ainda sentir através de toda uma série, não-reversível, de acontecimentos intermediários. Mas, para o homem político e para os que o seguem, a Revolução Francesa é uma realidade de outra ordem: sequuência de acontecimentos passados, mas também esquema dotado de uma eficácia permanente, permitindo interpretar a estrutura social da França atual, os antagonismos que nela se manifestam, e entrever os lineamentos da evolucão futura. [...] [É uma] dupla estrutura, ao mesmo tempo histórica e não-histórica. (Lévi-Strauss, 1975 [1955]: 241)
}

Esta comparação não deprecia a política nem o mito, já que a "lógica do pensamento mítico nos pareceu tão exigente quanto aquela na qual repousa o pensamento positivo e, no fundo, pouco diferente" (Lévi-Strauss, 1975 [1955]: 265). Ela trata da política, tanto quanto do mito, como uma relação entre diacronia e sincronia, entre incontroláveis acontecimentos passados e a concepção de recorrências como chaves para o que acontece agora e o que poderá acontecer depois. Assim também fazem pensadores como Nicolau Maquiavel, que estudou as condições de existência e estabilização de uma república baseado em conhecimentos sobre eventos passados e suas recorrências, "a longa experiência das coisas modernas e a contínua lição das antigas" (Maquiavel, 2018 [1513]), especialmente diante de momentos políticos conturbados, os "momentos maquiavelianos" (Pocock, 1975). Há um duplo sentido na noção de "momento maquiaveliano": podem ser quaisquer momentos críticos de reflexão sobre os fundamentos de uma república tanto quanto aquele momento histórico específico no qual entender e controlar os eventos aparentemente imprevisíveis do tempo secular tornou-se pela primeira vez uma questão, não prevista pelos costumes nem pelos céus (Mulgan, 1981).

De uma perspectiva lévi-straussiana sobre a relação entre política e mito, então, pode-se dizer que o "momento maquiaveliano" é aquele em que a política substitui o mito em seu papel de conjugar o tempo linear e o não-linear - e assim misturar historicidades "frias" e "quentes" (confira Goldman, 1999; Almeida, 1999). Ainda que haja neste caso a predominância da historicidade quente e 
entrópica, já que, segundo J. G. A. Pocock (1975), Maquiavel encara a corrupção e a decadência dos regimes como mais certas que a estabilidade, enquanto, de modo similar, Lévi-Strauss considera irreversível a tendência geral à entropia, a passagem de estados de ordem para estados de desordem (Almeida, 1999), tal qual uma fogueira que queima até às cinzas. Apesar desse pessimismo, LéviStrauss permite lidar com concepções de tempo indígenas nas quais historicidades "contra o estado" (Goldman, 1999) tentam conter a entropia, numa conexão direta com a mitologia. Ademais, considerar a política - ou a ideologia política ${ }^{3}$ - como tendo substituído o mito em formas políticas eurocoloniais justificaria o que dizem diversos ameríndios: "política é coisa de branco" (Perrone-Moisés, 2015).

Apontar para "momentos" de origem - a "primeira vez" - pode ser, todavia, uma forma de criar mitos - dotados de várias versões, como ensinou LéviStrauss. Assim, o Renascimento europeu teria sido o grande "momento" da secularização, no qual Maquiavel sugere ao príncipe que pareça religioso para aumentar sua popularidade - não por motivos celestiais -, chocando o pensamento cristão da época. Mas antes houvera o "momento" de Aristóteles dar conselhos semelhantes a governantes que, segundo o Estagirita, zelando pelos deuses, visavam mais os favores do povo que os divinos (confira Mulgan, 1981), aquele "momento" em que a Filosofia teria tomado o lugar do Mito no pensamento grego antigo 4 .

Enfim, de uma perspectiva mito-histórica, para além do estudo da origem da secularização, é importante comparar suas versões. Pocock mostra que o "momento maquiaveliano" tem muitas versões, tal qual a do "momento rousseauniano", presente na utopia da marcha para o Oeste norte-americana, uma transformação da guerra expansionista de Maquiavel (confira Pocock, 1975: 544-556). De todo modo, narrativas alternativas podem conviver ou entrar em conflito, interagir com histórias vizinhas ou ser contadas por vozes antes excluídas (Pocock, 2008: xv).

Assim como Lévi-Strauss, Pocock tem como referência metodológica o estruturalismo de Ferdinand de Saussure e a relação entre langue e parole (Silva, 2013). Para aquele, o mito pertence tanto ao campo da palavra (parole) quanto da língua (langue) - mas também a um terceiro campo, além do linguístico, fazendo com que a análise estrutural dos mitos não se sujeite a problemas de tradução (Lévi-Strauss, 1975 [1955]): mitos são narrativas que atravessam línguas e fronteiras, transformando-se (Almeida, 2009; Gow, 2014). Assim, apesar de lidarem com problemas semelhantes, o estruturalismo (ou pós-estruturalismo5) de Lévi-Strauss difere da "virada hermenêutica" de Pocock ao propor um método supra-linguístico e esquemático, baseado na compilação de "feixes de relações": conjuntos de enunciados (frases curtas contendo sujeito e predicado) que têm a mesma forma e cabem numa mesma função matemática ${ }^{6}$. Sua fórmula canônica constitui uma comparação entre quatro

\footnotetext{
3 O termo "ideologia" não consta da versão de 1955 do referido texto, onde não se lia "ideologia política" mas somente "política".

4 Confira Chiara Bottici para uma revisão crítica das narrativas que separam mithos e logos (2008), embaçando este "momento aristotélico". Ainda, outra versão do mito de origem da política foi discutida por Foucault (Elden, 2002) supostamente contra Maquiavel - analisando o discurso sobre a guerra como relação social permanente, mais precisamente na forma das narrativas sobre a "guerra de raças" que precederam o racismo no século XVI, ainda que pensadas não como um "momento" mas como uma tradição. Tal tradição pode ter influenciado as reflexões de Élisée Reclus sobre a "guerra de raças" americana, examinada adiante.

5 Confira Viveiros de Castro sobre Lévi-Strauss (2015 [2009]).
}

${ }^{6}$ De acordo com Mauro de Almeida, a fórmula de Lévi-Strauss parece algébrica mas é, de fato, topológica (2009: 25). 
funções, como será explanado na última parte do artigo7.

\section{Elementos republicanos}

Um indício para a comparação entre proposições anarquistas e republicanas aparece na semelhança entre as considerações de Proudhon sobre ciclos políticos e os conceitos republicanos de história (ver Pocock, 1975; Inglis e Robertson, 2006), uma ressonância da anaciclose ${ }^{8}$ republicana clássica na historicidade de Proudhon. A tradição republicana pode ser traçada de Aristóteles a Políbio, Maquiavel, Montesquieu, aos "Pais Fundadores" norteamericanos etc. Ela propõe formas de divisão de poder, governos mistos e arranjos institucionais para lidar com lutas de classes 9 e antagonismos políticos, o "conflito civil" (Cardoso, 2016). Um elemento comum dessas teorias é uma busca pelo balanceamento de forças opostas buscando estabilidade governamental.

Para Aristóteles, uma solução possível a fim de evitar o ciclo de constituição e corrupção de governos, dados os conflitos irreconciliáveis de um mundo não-ideal, seria uma mistura de oligarquia e democracia, lidando com a luta entre ricos e pobres, uma desigualdade de classe medida pela propriedade e atenuada pela conquista baseada numa classe média guerreira, de modo que a força da guerra de conquista garantiria a oposição entre cidadãos livres e escravos (Mulgan, 1981, 2000) ${ }^{10}$. Este modelo político ateniense seria considerado, mais tarde, não tão virtuoso quanto o romano que, em meio a tantos conflitos civis, faria emergir uma "constituição admirada por Políbio e estável o bastante para conquistar o mundo" (Pocock, 1975: 189 - minha tradução).

Maquiavel responderia, a seu modo, aos mesmos problemas (Pocock, 1975), mas radicalizando a positividade do conflito civil para a durabilidade de uma constituição política (Cardoso, 2016). Uma consideração maquiaveliana adicional sobre luta de classes - a ser comparada adiante à visão perspectivista de Proudhon sobre autoridade e liberdade e ao perspectivismo ameríndio - é que o autor florentino reconhece nela uma diferença de perspectivas: existem os grandes que desejam dominar e acumular poder, enquanto o povo deseja apenas ser livre. As perspectivas da elite e do povo não competem pelo mesmo objetivo. Apesar de comentaristas de Maquiavel argumentarem sobre a possibilidade de ambos os desejos tornarem-se o mesmo, não há concordância sobre como isso ocorreria (Ferreira, 2016). De todo modo, para Maquiavel, mesmo desejoso da liberdade, o povo se submete ao governo dos grandes. A

\footnotetext{
7 A comparação que acabo de fazer entre as metodologias de Lévi-Strauss e Pocock não pretende ser exaustiva, lidando apenas com a possibilidade de abordar semelhanças entre enunciados políticos e míticos através da proximidade entre ambas.

${ }^{8}$ Anti-ciclo, isto é, tentativa de contenção ou escape do ciclo vicioso das formas de governo gerado pelo antagonismo entre grupos sociais desiguais.

9 Aqui se aproxima de uma noção política de classe, como a de Maquiavel ("grandes" versus "povo"), a despeito do conceito econômico defendido por Karl Marx, criticado por Pierre Clastres ao demonstrar que a premissa do materialismo histórico dialético, de que transformações nas relações sociopolíticas dependem de transformações nas forças produtivas, não ocorre na América indígena: enquanto caçadores e coletores podem ter a mesma "superestrutura" de povos agricultores, impérios meso-americanos tinham agricultura semelhante àquela praticada por "sociedades contra o Estado" (Clastres, 2003 [1974]). Ora, poder-se-ia contra-argumentar que é por isso que não há classes na América indígena, o que não invalidaria a anterioridade da exploração econômica em relação à dominação política para casos não-amerídios: em resposta a isto, ver a próxima nota de rodapé.

${ }_{10}$ Aristóteles, ao conceber o "homem" como animal político, caracteriza a política como organização para o trabalho comum, ainda que baseada na dominação do servo pelo amo (ou do escravo pelo cidadão), da esposa pelo marido e do filho pelo pai, o que apontaria para a hipótese clastriana de que a relação de poder funda a exploração econômica (Martín, 2016).
} 
chave desta submissão, encontrada na república romana, estaria num certo acesso ao poder concedido pelos grandes ao povo: cidadania, assembleias populares e tribunos da plebe, por um lado, e por outro a participação popular no exército de modo a aproximar o povo do desejo elitista de conquista e escravização (confira Ferreira, 2016), permitindo períodos de estabilização do conflito interno.

Maquiavel também alerta, em seus Discorsi, para o perigo do aumento do desejo popular por poder - aproximando tal desejo, paradoxalmente, da perspectiva dos grandes - diante da oposição da elite às reformas sociais (como a reforma agrária e a distribuição de propriedade), evoluindo rumo à corrupção da república (Ferreira, 2016) e à tirania. Isto faz eco na concepção de Proudhon a respeito do Império como um tipo de governo misto, popular mas autoritário: "democracia autocrática" (Proudhon, 2001 [1863]). Além disso, um elemento dos Discorsi de Maquiavel que pode ser aproximado ao republicanismo federalista americano é o elogio à constituição do poderio romano através de uma liga de estados aliados sob o comando centralizado da cidade de Roma, ao invés de uma confederação (livro dois, capítulo quatro), uma espécie de federalismo centralizado.

Séculos depois, a centralização defendida e realizada pelos republicanos norte-americanos foi fundada em transformações do conceito de conflito civil, não concebendo-o propriamente como luta de classes, senão como conflito entre indivíduos e facções. Se, para o republicanismo clássico, a história cíclica está ligada ao conflito entre estratos sociais hierarquicamente relacionados e antagônicos, segundo Pocock o escape dos ciclos políticos ou do tempo dialético nos Estados Unidos da América não teria sido realizado no tempo, mas no espaço: na marcha para o Oeste, utopia de pequenos fazendeiros, popularizando o desejo de conquistar terras (Pocock, 1975).

Os Federalistas pressupõem o desejo egoísta de acumulação e poder como um vício de todos, sem distinção de perspectiva entre povo e elite. De modo que o medo de uma facção forte - e não da força do povo subalternizado - foi a motivação alegada para a constituição de um federalismo centralizado num país de território de tamanho imperial como os EUA ${ }^{11}$. Por isso, uma democracia representativa eleitoral e um território federal grande, de modo a diversificar interesses, preveniria a formação da tirania da maioria, inclusive devido à maior propensão de grandes proprietários a vencer as eleições (Limongi in Weffort, 1996; Penna, 2011). Não obstante, há nos Federalistas uma referência ao governo misto de Montesquieu, porém esvaziada de reminiscências estamentais ou classistas, compondo o federalismo norte-americano com a tripartição de poder que, assim dividido, obrigaria as facções a cooperarem graças aos "freios e contrapesos" que as impediriam de impor a força umas sobre as outras (Limongi in Weffort, 1996).

Todavia, conforme teses anarquistas a seguir, tal balanço de poder entre facções, além de reforçar a identidade entre elite e povo brancos, teria sido feito às custas de povos negros e indígenas, subalternizados cuja força era temida. Ora, a utópica marcha para o Oeste foi uma guerra genocida contra povos ameríndios. 


\section{Elementos anarquistas}

Já o federalismo de Proudhon também visa escapar daqueles ciclos, mas sem ignorar a luta de classes. Proudhon dá um giro copernicano à anaciclose, como se a Terra fosse a Autoridade e o Sol a Liberdade. A história do Velho Mundo é mostrada em Do Princípio Federativo (2001 [1863]) como uma alternância instável de posições de classe em relação à autoridade: elites podem fazer uso da democracia para dominar; a multidão é volúvel e apoia ditaduras; sistemas políticos e golpes de estado sucedem-se uns aos outros sem proporcionar um escape da dominação unitária ${ }^{12}$. Ao criticar as tomadas violentas de poder, Proudhon tratou as associações de apoio mútuo populares e o federalismo proletário local e internacional do século XIX como uma ruptura do ciclo vicioso político e a prefiguração de um modo de vida socialista anárquico: o federalismo agro-industrial republicano, uma maneira pacífica e produtiva de dar conta da pulsão competitiva humana, atenuando ou evitando a guerra (Proudhon, 1861, 2001 [1863], 1986).

Portanto Proudhon combina a história política cíclica a uma certa evolução - ou revolução - de modo que a razão ${ }^{13}$ política rume da Autoridade para a Liberdade, realçando esta sem eliminar totalmente aquela. Ao buscar estabilidade, colocando a liberdade acima da autoridade, o poder é pulverizado de modo federativo com base na delegação da autoridade mas não na centralização. $\mathrm{O}$ mesmo se passa com a propriedade: só seria aceita a posse direta no modo de produção mutualista, baseado na reciprocidade. "Em resumo, o sistema federativo é o oposto da hierarquia ou centralização administrativa e governamental a qual distingue, ex aequo, as democracias imperiais, as monarquias constitucionais e as republicas unitárias" (Proudhon, 2001 [1863]: 91), sendo essas três ultimas as formas de governo misto reais.

Com essa teoria, Proudhon renega o caráter libertário do federalismo norte-americano: "Pois bem! Quais eram então as ideias, em matéria política, dos americanos? Quais foram os princípios do seu governo? Uma verdadeira embrulhada de privilégios; um monumento de intolerância, de exclusão e arbitrariedade, onde brilhava, como um astro sinistro, o espírito da aristocracia, da regulamentação, de seita e casta", com uma rígida distinção entre brancos e negros (2001 [1863]: 111, passim).

Outra crítica ao republicanismo federativo americano, considerando não só os EUA mas também o Brasil - que mais tarde adotaria uma combinação de federalismo centralizado e tripartição de poderes semelhante à dos EUA - foi feita por Élisée Reclus, familiarizado com as ideias de Proudhon apresentadas em obras mais antigas (Ferretti, 2016). Reclus sugere que a perspectiva republicana liberal ignora a desigualdade racista desses dois países, comparados por ele não só na relação do patriarcado branco com o povo negro mas também com povos indígenas, assimilados ou exterminados, estando o autor atento a algumas questões hoje chamadas de interseccionais (Reclus, 2011 [1862]; Ferretti, 2015, 2018; Skoda, 2016).

Décadas antes da proclamação da república no Brasil, Reclus já apontava para a formação de laços federativos entre as elites locais das diversas províncias brasileiras a fim de lidarem com coletivos subalternos ou rebeldes, negros e indígenas. Estes laços constituiriam mais tarde a República Federativa

${ }_{12}$ Apesar do surgimento de algumas organizações confederativas que teriam sido derrotadas na Europa antiga pela expansão romana, ou vencidas na França revolucionária pelo poder unitário, senão organizadas de modo aristocrático como a Suíça.

${ }_{13}$ "Razão" tem aqui o sentido de relação entre diferenças, conforme a dialética serial de Proudhon (Borba 2004). 
do Brasil, de modo que os argumentos de Reclus são confirmados por diversas análises atuais (confira Mercadante, 1980; Azevedo, 1987; Dolhnikoff, 2004; Guimarães, 2011). Reclus (2011 [1862]) apresenta uma espécie de dialética entre a manutenção do poder pela elite e a "guerra de raças": intentonas republicanas locais falharam em diversas partes do Império do Brasil, fortalecendo um processo de reconciliação dos patriarcados brancos provinciais rumo a um federalismo republicano centralista, uma solidariedade elitista diante de um inimigo comum: as "raças" subalternizadas (Reclus, 2011 [1862])14. Concebendo os povos indígenas como uma "raça", imaginou a mestiçagem, mistura das "raças", como uma solução para a política racista (Ferretti, 2013; Pinto, 2015) uma posição comum a diversos adversários do racismo na época, como o haitiano e pioneiro da Antropologia, Ántenor Firmin (1885) ${ }^{15}$.

A escravidão no Brasil terminaria oficialmente no final do século XIX. Rui Barbosa, famoso republicano daquele tempo, dizia que "escravidão é roubo" (Silva, 2000), uma paródia da mais famosa frase de Proudhon, "propriedade é roubo", jamais aceita por Rui, defensor da propriedade - que não seria redistribuída ao povo negro após a abolição da escravatura. Ora, o fim da escravidão também não acabou com o racismo: o branqueamento foi uma política de estado na virada do Império à República, muitas vezes associado ao ideal da mestiçagem (Schwarcz 1996, Munanga 1999). O caráter problemático da ideologia da mestiçagem em relação à negritude seria criticado apenas no final do século XX (confira Costa, 2001; Domingues, 2007; Felix, 2009).

\section{Elementos ameríndios}

Agora, estudos sobre (cosmo) políticas ameríndias tem apontado para algo que seria uma segunda torção na mencionada virada copernicana proudhoniana: um giro contra a estabilidade.

Minha pesquisa prévia e independente comparou o federalismo anarquista a um certo (con)federalismo ameríndio (Falleiros, 2015, 2016, 2017) com base em investigações sobre formas políticas ameríndias (Perrone-Moisés, 2006, 2011; Perrone-Moisés e Sztutman, 2009, 2010; Sztutman, 2005, 2011, 2013) que combinam o trabalho de Pierre e Helene Clastres ao "dualismo em perpétuo desequilíbrio" (Lévi-Strauss, 1995 [1991]) de mitologias e filosofias indígenas, "feito política" ao afetar a distribuição de poder a partir de topologias e temporalidades pendulares, oscilando entre pequenos coletivos e grandes confederações. O que vai ao encontro de alguns argumentos do "dualismo político" federalista de Proudhon (2001 [1863]), no qual a reversão da relação entre liberdade e autoridade lembra o giro copernicano de Pierre Clastres "contra o Estado" (2003 [1974]).

Essas coincidências foram encontradas traçando a influência de Proudhon sobre Lévi-Strauss através de Célestin Bouglé (2014 [1911]), orientador da famosa tese de Lévi-Strauss, na qual este faz referências diretas a Proudhon.

\footnotetext{
${ }^{14}$ Reclus foi provavelmente influenciado pelo uso da expressão "guerra de raças" aplicado à Cabanagem por políticos da época: segundo André Machado, a expressão foi concebida por uma noção bastante flexível de "raça", na qual eram incluídos indígenas menos e mais cristianizados, majoritariamente empregados em trabalhos compulsórios, junto de negros e até mesmo brancos - o que não invalidaria a questão racial como marcante no conflito (Machado 2016).

15 Sobre a "a igualdade das raças humanas", Firmin defende a mestiçagem como demonstração da falácia do racismo, sendo "um fato de ordem puramente fisiológica e nada mais" (Firmin, 1885: 308 - minha tradução). Na mesma obra, Firmin cita as pesquisas geográficas de Reclus sobre a África, contra a teoria racista de Gobineau, para recusar tanto a suposta padronização racial dos tipos físicos naquele continente quanto a prevalência do orgulho de raça entre povos africanos.
} 
Tais influências encontram-se nos primeiros trabalhos de Lévi-Strauss não somente sobre parentesco mas também reciprocidade, hierarquia, passando pela dialética serial de O Pensamento Selvagem e culminando em seus estudos sobre mitologia (Falleiros, 2016). Daí, pesquisas etnográficas influenciadas pelo "dualismo em perpétuo desequilíbrio feito política", como minha própria com os A'uwe-Xavante (Falleiros, 2012a), podem ser lidas como encontrando, em modos de vida ameríndios, derivas críticas ao anarquismo, assim como conceitos de Lévi-Strauss derivam criticamente dos de Proudhon.

Tais desvios são trazidos pelo cruzamento ameríndio de diferentes perspectivas sobre a mesma relação, constituindo novas séries através da anterior, apresentando-se em topologias excêntricas ou multi-centradas, de inversões estruturais anti-hierárquicas (Lima, 2008), parentesco não-patriarcal, a abertura ao outro e outros elementos detalhados em meus trabalhos previamente citados. Há uma opção pelo desvio que se manifesta também no fazer (cosmo)político indígena, como na "esquiva do xondaro" guarani mbya (Keese, 2017) ou na "lateralidade" waiwai (Zea, 2010)16. Tomo essas formas como um fundo para a organização, a partir de sua lógica, de elementos que lhes são alheios, o que seria uma atitude característica de pensamentos ameríndios (confira Sztutman e Matarezio Filho, 2015).

Assim, em referência a estes elementos alheios, deve ser lembrado que Maquiavel já havia proposto duas perspectivas diversas sobre a mesma relação política, o que apresenta certa semelhança com o perspectivismo topológico ameríndio (confira Lima, 2008, Falleiros, 2016). Mas algo de sua teoria de classes certamente não cabe aí. Por exemplo, nos seus Discorsi, Maquiavel nota que a elite romana concentrava poder, enquanto permitia à plebe a honra de ocupar algumas magistraturas (Ferreira, 2016). Todavia, em diversas formas políticas ameríndias, é o oposto que acontece: o povo toma as possessões de seus líderes, permitindo-lhes, contudo, honra e glória (Lévi-Strauss, 1944b; Lowie, 1960 [1948]; Clastres, 2003 [1974]; Perrone-Moisés, 2011; Falleiros, 2012c, 2013a). Isto significaria a inversão da autoridade dos grandes: servis, aqueles que vão primeiro para o trabalho, para a festa ou para a guerra (Sztutman, 2005), agindo como anfitriões (Perrone-Moisés, 2015), ganham prestígio através de sua habilidade de congregar pessoas, o que pode ser facilmente perdido para o separatismo - como quando líderes A'uwe-Xavante não cumprem com a demanda para que diferenças de opinião coletivas se expressem em suas falas (Maybury-Lewis 1984 [1967]; Falleiros, 2010, 2012a, 2013b).

Bem longe de Roma, Pierre Clastres, assim como Maquiavel, fala da importância do povo em armas - mas "contra o Estado" (Clastres, 2003 [1974], 2004 [1980]), de modo que, proudhonianamente, a liberdade supere a autoridade, ainda que sem destruí-la, ao contrário do que ocorre na república maquiaveliana, onde a autoridade dos grandes supera a liberdade do povo apesar de não eliminá-la por completo. Em diversas paragens da América indígena a guerra se expressa como cisão ${ }^{17}$, de modo que a ruptura é garantia de liberdade. Isso leva a historicidades pendulares "contra o estável" (Macedo, 2011), alternando a formação de coletivos entre os polos do "contra-Estado" e do

${ }^{16}$ Curiosamente, neste texto, Evelyn Zea aponta para obras de Saussure que abordam a relação entre língua e mito, considerando transformações que Lévi-Strauss via no campo do mito acontecendo dentro da própria língua, elidindo a visão geral mais conservadora que se tem do autor.

${ }_{17}$ Por exemplo, Pedro Viana (2013) questiona tentativa hobbesiana de Santos-Granero de desqualificar esta hipótese a respeito dos Aruaque a partir de dados Ashaninka, argumentando que não se pode falar em "interdição da endoguerra" quando "dentro" e "fora" são delimitações instáveis, e apontando para a bruxaria como princípio faccionalista responsável por conflitos centrífugos (Viana 2017). 
“quase-Estado" (Perrone-Moisés, 2006; Perrone-Moisés e Sztutman, 2010).

Portanto, diferentemente da busca republicana de Proudhon por estabilidade, aqui é a instabilidade que garante a liberdade. A liderança não é simplesmente delegada, nem as relações são baseadas numa mutualidade igualitária e equilibrada: líderes tornam-se grandes apesar de subordinados ao povo através da dádiva ou da predação (Falleiros, 2012c, 2013a). Há também alternância de autoridade e liberdade entre a perspectiva dos líderes e do povo, em formas complexas de subordinações recíprocas que relacionam não só pessoas a seus líderes mas também vários coletivos entre si.

Povos como os A'uwe-Xavante fazem-se por diversos pertencimentos coletivos entre-cruzados: grupos de idade, metades cerimoniais, metades exogâmicas, patrilinhas e matricasas (Falleiros, 2010a, 2010b, 2012a) etc. Aqui o parentesco não cria uma miscigenação sintética das pessoas, já que as diferenças existentes são chaves para as alternâncias de poder e mudanças de posição, dependendo de qual forma de pertencimento for acionada a cada momento. Isso se dá mesmo na relação entre os conceitos nativos de indígena e não-indígena, como no caso dos Karajá (Nunes, 2014), em que a mesma pessoa se assume karajá (iny) ou "branca" (tori, palavra que não se refere à cor da pele, já que a concepção indígena diferença não é racializada) dependendo do momento, da atitude ou da relação em causa, de modo que a pessoa adquire um "segundo ponto de vista", numa mistura sem síntese - o que contraria as concepções políticas de raça dominantes no mundo não-indígena. Até as próprias clivagens do mesmo coletivo podem ser concebidas diferentemente dependendo da perspectiva: pessoas de um lado podem conceber sua relação com as pessoas do outro como duas metades, enquanto as pessoas do outro podem conceber sua relação com as demais como a do centro com a periferia (Lévi-Strauss, 1944a, 1958), daí não haver uma busca por igualdade mas sim por paridade: simetrização de relações assimétricas (Lima, 2008).

Deste modo, não existem estamentos ou classes, tampouco unidades de medida universais ("equivalentes gerais" como o dinheiro) servem para calcular quem é mais do que quem, pois nenhuma perspectiva engloba a outra.

A própria relação entre centro e periferia pode ser invertida, considerandose certas topologias indígenas como panópticos invertidos (Sztutman, 2005: 255), o que se manifesta nas relações de gênero dos A'uwe-Xavante (Falleiros, 2016). Inversões de hierarquia e assimetrias recíprocas de gênero, liderança etc., têm sido identificadas entre diversos povos, até mesmo entre os supostamente aristocráticos Kadiwéu (Freire, 2018).

\section{A fórmula canônica e a série (cosmo)política}

Apesar de todas essas questões que complicariam a equiparação entre políticas ameríndias e republicanas, estas já foram consideradas semelhantes. Élisée Reclus aplicava o termo "república" a qualquer organização política fundada na liberdade: segundo ele, os "Esquimós" (Inuit), por exemplo, viviam em "pequenas repúblicas" (Ferretti, 2016: 10). Já o republicanismo federativo norte-americano teria sido inspirado, de acordo com alguns de seus fundadores, na Liga Iroquesa, hipótese apoiada por Henry Lewis Morgan (1877) em controvérsia examinada por Brian Cook (2000), sendo que a resposta afirmativa faria supor que nos EUA os líderes seriam servos do povo, e não seus senhores. Todavia, como visto, análises anarquistas apontam para a prevalência da 
concentração de propriedade e de autoridade no federalismo centralista dos EUA. Por outro lado, Proudhon, ignorando a tese da influência iroquesa, considerava como fontes de liberdade para o federalismo norte-americano somente a influência francesa e o "individualismo anglo-saxônico lançado nas imensas solidões” da América (2001 [2001]: 112) - o que remete à hipótese de Pocock sobre o "momento rousseauniano" utópico da marcha para o Oeste -, sem valorizar a presença e a agência indígenas.

Diante destas dificuldades comparativas, proponho uma metodologia influenciada pela agência ameríndia, adotando uma perspectiva a partir da qual pode ser feita uma comparação rigorosa entre formas políticas. Assim, na fórmula canônica do mito serão inseridas sentenças que condensam as proposições a respeito do republicanismo clássico, do republicanismo federativo americano, do anarquismo e das formas políticas ameríndias. Isso pode parecer uma aproximação bruta, mas é assim que Lévi-Strauss propunha que fosse, uma comparação em linhas gerais. Considerando que, para o autor, menos preocupado com fidelidade às origens do que com transformações, toda história é a versão de uma outra, haverá diferenças entre minha reconstrução destes argumentos e outras reconstruções ${ }^{18}$. Ainda assim, o uso desta ferramenta é um teste, uma hipótese tentativa, buscando o sucesso pragmático mais do que uma demonstração exaustiva. De todo modo, parece coerente com o uso dado por Lévi-Strauss como uma ferramenta para o diálogo, desde as primeiras formulações programáticas até escritos mais recentes, conectando "objetos culturais" histórica e geograficamente descontínuos (Almeida, 2009: 2) ou, melhor, mudanças de perspectiva.

Usarei duas das versões da fórmula canônica, a "original” (A) e aquela que Lévi-Strauss aplica ao mito de Édipo (B):

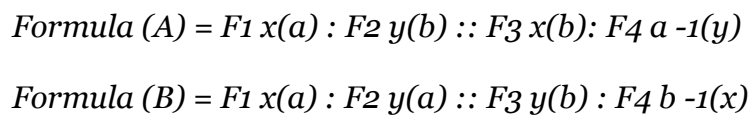

Lévi-Strauss teria usado diversas versões da fórmula ao longo de sua obra e talvez esta última (B) sirva ao estudo de um mito particular, enquanto a anterior (A) seja melhor aplicada ao cruzamento entre mitos (Mauro Almeida, comunicação pessoal). De todo modo, a característica distintiva da fórmula é a introdução de uma assimetria (na quarta função) no que outras análises comparativas sugeririam uma analogia simples. Relendo Proudhon deste ponto de vista, pode-se considerar essa assimetria como uma resposta a perturbações reais na progressão da série lógica original, resultando numa lógica mais complexa, capaz de cruzar mais de uma série. Enfim, ao invés de utilizar a morfologia de Vladmir Propp buscando invariantes, o método trata as narrativas como transformações umas das outras, sujeitas à história, numa lógica não-orientada e aberta à historicidade (Almeida, 2009: 26).

Abaixo segue resumida a apresentação de Almeida (2009) sobre o uso da fórmula (B) por Lévi-Strauss na análise do mito de Édipo (1975 [1955]) conforme sua interpretação do caráter político dos personagens "mancos", seguido de rápida demonstração:

(FI) incesto (relações internas exageradas na família dos tiranos estrangeiros de Tebas, os Labdácidas: Cadmo, Laio, Édipo etc.) está para (F2) parricídio e fratricídio

18 Pelo menos, na comparação entre tais versões, pode ser sugerida a aplicação do mesmo método, num campo mais restrito, relacionando mais versões, lembrando que Lévi-Strauss fez o mesmo, escrutinando mitos específicos compilados nas Mitológicas. 
(conflito interno aos Labdácidas) assim como (F3) guerra contra o povo nativo (os Espartos, habitantes indígenas de Tebas "semeados" por Cadmo dos dentes do dragão que matou) está para (F4) as deformidades e assimetrias da tirania.

Cada parte da fórmula (1, 2, 3 e 4) é uma função (F). Cada função resume um conjunto de relações, isto é, de afirmações cuja relação entre sujeito e predicado (sentenças curtas que resumem a narrativa) encontra um certo paralelo. A função (1) lida com relações de parentesco endogâmicas exageradas, sendo um feixe das seguintes relações análogas: "Cadmo vai atrás de sua esposa Europa, raptada por Zeus", "Édipo se casa com sua mãe, Jocasta", "Antígona enterra seu próprio irmão, Polinice, violando uma interdição" etc. Função (2) lida com relações de parentesco endogâmicas subestimadas ou de conflito interno fatal, conforme o feixe das seguintes frases "Édipo mata seu pai, Laio", "Etéocles mata seu irmão, Polinice" etc. A função (3) lida com relações subestimadas ou conflitos fatais entre estrangeiros e autóctones e, segundo Lévi-Strauss, congrega afirmações como "Cadmo mata o dragão" (habitante original do local, do qual Cadmo tomou os dentes que semeou), "os Espartos são quase exterminados" etc. Bem, a função (4), de acordo com uma analogia simples, poderia ser pensada como um feixe de relações de superestima entre estrangeiros e nativos: alianças entre Labdácidas e Espartos: "Cadmo dá sua filha Agave como esposa para Ctônio", "Lábdaco, órfão de Polidoro, quando criança, dá a regência de Tebas para Nicteu, filho de Ctônio" etc. - todas estas afirmações se encontram na mitologia de Tebas e fazem sentido de acordo com a análise europeia tradicional da estrutura do mito por dedução analógica...

Todavia, Lévi-Strauss propõe algo diverso: uma dupla torção, abordando uma perspetiva diferente sobre a série, a partir da etimologia dos nomes Labdácidas, referida a deformidades no corpo e na comunicação (características ausentes entre os autóctones) expressas da seguinte forma: "Édipo tem o pé inchado", Lábdaco é manco", "Laio é canhoto e gago" etc., considerando-as assim inversões da autoctonia, de modo que a função (4), duplamente torcida, trata do caráter manco, assimétrico, da superestima: a tirania. Estas estranhas reviravoltas aplicadas por Lévi-Srauss à função (4) foram criticadas por helenistas, mas Jean-Pierre Vernant, em sua defesa, encontrou um grupo de mitos gregos sobre Labda, a manca, de Corinto, nos quais são abertamente abordadas as características assimétricas, abusivas e incestuosas da tirania (Almeida, 2009).

Feita esta exposição, antes de abordar as comparações gerais prometidas acima, sou tentado a aplicar a fórmula canônica (B) sobre a narrativa do republicanismo federativo americano apresentada por Élisée Reclus - dando a ela uma reviravolta no final -, já que tanto a mitologia de Édipo quanto a análise política reclusiana lidam com relações entre colonizadores estrangeiros e povos autóctones:

Alianças (x) entre elites (a) [federalismo centralizado]: Separação e conflito (y) entre elites (a) [intentonas republicanas locais] :: Separação e conflito (y) entre elite $e$ indígenas (b) [guerra de raças]: Branqueamento $(b-1)$ das alianças $(x)$ [mestiçagem subsumida pela política de branqueamento].

Como mencionado, Reclus foi entusiasta da miscigenação como alternativa de superação do racismo, uma abordagem que, por analogia simples (sem dupla torção), tomaria a forma de aliança (x) entre elite e indígenas (b): $\mathrm{F} 4 \mathrm{x}(\mathrm{b})$. Contudo, a mestiçagem sintética seria um instrumento de dominação colonial, diferente de formas ameríndias de aliança (Kelly, 2016) que, como sugere Eduardo Nunes (2014), não operam a mistura como síntese - o que resulta num 
englobamento da mestiçagem pelo branqueamento - mas sim uma duplicação de perspectivas alternadas na mesma pessoa. Uma operação semelhante (duplicidade de perspectivas ao invés da suposta síntese) foi identificada por Silvia Rivera Cusicanqui na relação entre anarquismo e pensamento ameríndio feita por seu tio, Luis Cusicanqui, em manifesto dirigido a indígenas e camponeses bolivianos, com forte influência da temporalidade mítica aymara (Rivera, 2015), de modo que um anarquismo crítico à colonização só pode se aliar à perspectiva indígena se atravessado por ela, numa dialética sem síntese. A supramencionada hipótese de Samuel Barbosa de simetria jurídica entre indígenas e constituinte de 88, demandando uma "ecologia de saberes" para a interpretação da constituição, o que vai além da doutrina jurídica, estaria numa situação semelhante de dialética sem síntese, não fosse a judicialização da política e o ponto cíclico de autoritarismo atualmente instalado, consequências do federalismo republicano brasileiro e seus elementos estruturantes (patriarcado branco, colonialismo, centralismo, propriedade).

Finalmente, aí se confirma uma das vantagens do uso da dupla torção: a identificação de um elemento factual (Almeida, 2009) perturbando a dedução analógica que supunha possível uma aliança igualitária entre colonizadores e indígenas, introduzindo na série a perspectiva histórica do branqueamento sobre a mestiçagem: um englobamento hierárquico no qual a característica corporal colonizadora - o colorismo e a racialização - é a inversão (b-1) do indígena.

Assim, a mesma fórmula (B), aplicada aos argumentos de Proudhon, resulta numa dupla torção, introduzindo um quarto modelo, não previsto pelo autor, formalmente semelhante às características de certos poderes ameríndios:

\begin{abstract}
A elite (x) está com a autoridade (a) [monarquia constitucional] : O povo (y) está com a autoridade [democracia imperial] $: \because O$ povo (y) está com a liberdade [federalismo anarquista] : A servidão (b-1) está com a elite $(x)$ [liderança servil ameríndia]
\end{abstract}

Para terminar, ao utilizar a fórmula (A) para relacionar, a cada função, formas políticas distintas entre si - republicanismo, anarquismo e formas ameríndias - tem-se os seguintes esquemas, que abrem as considerações deste artigo para reflexões especulativas:

Acúmulo de propriedade (x) via centralização (a) [republicanismo tradicional] : Mutualismo (y) via federalização (b) [anarquismo] :: Acúmulo de propriedade ( $x$ ) via federalização (b) [republicanismo norte-americano e brasileiro] : Excentrismo (a-1) via mutualização (y) [subordinações recíprocas multi-centradas ameríndias]

Estabilidade ( $x$ ) graças à diferença entre perspectivas de classe (a) [república romana em Maquiavel] : Instabilidade (y) graças ao assemelhamento de perspectivas de classe (b) [corrupção da república romana em Maquiavel] :: Estabilidade ( $x$ ) graças ao assemelhamento de perspectivas de classe (b) [mutualismo proletário em Proudhon] : Perspectivas não-classistas (a-1) graças à instabilidade (y) [perspectivismo ameríndio feito política].

Outras formulações poderiam ser ensaiadas - por exemplo, uma que lidasse com as diferentes perspectivas sobre a guerra: conquista, cisão, "guerra de raças" e violência atenuada. Ou que lidasse com a relação entre secularização política e cosmopolítica não-humana. ${ }^{19}$

19 Sobre violência atenuada, ver a relação entre gerra, jogo e festa (Falleiros, 2016) encontrada em diversos exemplos ameríndios (Lévi-Strauss, 2008 [1962], 2011 [1971]; Vianna, 2001; Perrone-Moisés, 2015). Sobre secularização política e 
Enfim, uma das vantagens deste método comparativo assim aplicado é a abertura para perturbações históricas na lógica dos ideais políticos, tanto quanto para a alteridade. $\mathrm{O}$ que podemos fazer com estas comparações é outra história. Todavia, uma história com potencialmente aberta a demandas indígenas sobre a política, esta "coisa de branco".

Recebido em 12 de setembro de 2018.

Aprovado em 7 de maio de 2019.

\section{Referências}

ALMEIDA, Mauro de. 2009. "A fórmula canônica do mito". Corrected version of the paper originally published in QUEIROZ, Ruben C. de \& NOBRE, Renarde F. (eds.). Lévi-Strauss. Leituras Brasileiras. Belo Horizonte, Editora da Universidade Federal de Minas Gerais, 2008.

AZEVEDO, Celia Maria Marinho de. Onda Negra, Medo Branco - O negro no imaginário das elites - Século XIX. Rio de Janeiro, Paz e Terra, 1987.

BORBA, João. Um relativismo de base cética na dialética de Proudhon. Verve, São Paulo: Nu-Sol., n.5, p. 142-56, 2004.

BOUGLÉ, Célestin. A sociologia de Proudhon. São Paulo, Imaginário, 2014 [1911].

BOTTICI, Chiara. "Mythos and Logos: A Genealogical Approach” Epoché, Volume 13, Issue 1, 2008. p. 1-24.

CARDOSO, Sérgio. "Em direção ao núcleo da 'obra Maquiavel': sobre a divisão civil e suas interpretações”. discurso, 45, (2), 2016, p. 207-248.

CLASTRES, Pierre. A sociedade contra o Estado. São Paulo, Cosac Naify, 2003 [1974].

[1980].

Arqueologia da violência. Cosac \& Naify, São Paulo, 2004

COOK, Brian. "Iroquois Confederacy and the Influence Thesis." Campton Elementary School, Tilton School, 11 Dec. 2000, Disponível em:<www.ces.sau48.org/iroqconf.htm>. Acesso em: jul. 2018.

COSTA, Sérgio. "A mestiçagem e seus contrários: etnicidade e nacionalidade no Brasil contemporâneo." Tempo social, 13.1, 2001, p.143-158.

DOLHNIKOFF, Míriam. "A regionalização do jogo político - Elites e poder legislativo no Brasil do século XIX”, Novos Estudos, 70, São Paulo, CEBRAP, 2004, p.33-49.

cosmopolítica não-humana, ver estudo etnográfico da relação entre anarquistas e astrologia no qual se aplicam algumas das ideias aqui mencionadas (Falleiros, 2018b). 
DOMINGUES, Petrônio. Movimento negro brasileiro: alguns apontamentos históricos. Tempo, 12.23, 2007.

ELDEN, Stuart."The War of Races and the Constitution of the State: Foucault's "Il faut défendre la société» and the Politics of Calculation", Boundary 2, n.29, v.1, Duke University Press, 2002.

FALLEIROS, G. "Casas, corpos, nomes e outras dádivas - hipóteses sobre reciprocidade e tradiçãoa'uwẽ- xavante”. In: AMADO, Roseane de Sá (org.). Estudos em línguas e culturas Macro-Jê. São Paulo. Paulistana, 2010a.

- "Políticas musicais e corporações corporais: de Mauss aos A’uwẽ-Xavante”, 27a Reunião Brasileira de Antropologia, Belém do Pará, $2010 b$.

. Datsi'a'uwẽdzé: vir a ser e não ser gente no Brasil Central. Tese de doutorado, Antropologia Social, Universidade de São Paulo, 2012a.

. "Predando a Dádiva do Estado", Movimientos indígenas y sus aportes al debate político en América Latina, III Congreso de Antropología Latinoamericana, Santiago, Chile, 2012c.

. Vir a ser e não ser gente através da participação etnográfica no

Brasil Central. Universitas Humanística, n. 75, Bogotá, Pontificia Universidad Javeriana, 2013a, p. 251-74.

. "Chefes de grupo e grupos de chefes". Chefia, Política e Hierarquia na América indígena, $\mathrm{X}$ Reunião de Antropologia do Mercosul, Córdoba (Argentina), 2013b.

. "Entre Proudhon, Lévi-Strauss e além - Anarquismo protoestruturalista e dualismo perspectivo". Revista da Biblioteca Terra Livre, Ano 1, N. 2, 2015, p. 45-58.

. "Dialética perspectivista anarcoindígena". Cadernos de Campo, v. 25, n. 5, São Paulo, 2016, p. 107-130.

"Notas para uma crítica anarco-indígena do indivíduo". Palimpsestos: Revista de Arqueología y Antropología Anarquista, n. o, Ano 1, 2017, p.189-208.

. "From Proudhon to Lévi-Strauss and beyond - a dialogue between anarchism and indigenous America”, Anarchist Studies, v. 26, n.2, Lawrence \& Wishart, 2018a.

"Race, class, gender and zodiac signs", Journal des Anthropologues, n.152-153, 2018b, p.9-28.

FELIX, João Batista de Jesus. "As Primeras Formas de Lutas Contra o Racismo no Brasil Republicano." Tempo da Ciência 16.32, 2009, p. 67-79.

FERREIRA, Christiane. "Os conflitos civis em Maquiavel: o problema dos humores”. Tese de doutorado, Faculdade de Filosofia, Universidade de São Paulo, 2016.

FERRETTI, Federico. “Eles tem o direito de expulsar-nos': a Nova Geografia Universal de Élisée Reclus”. Revista Brasileira de Geografia Econômica, 2013. ameríndios: questões científicas e políticas”. Élisée - Revista de Geografia da 
UEG, v. 4, n. 1, 2015. p.36-52.

. "Breve cronologia da vida de Élisée Reclus (1830-1905)", Terra Brasilis (Nova Série). Revista da Rede Brasileira de História da Geografia e Geografia Histórica, n. 7, 2016.

.Élisée Reclus in Louisiana (1853-1855): Encounters with Racism and Slavery". The AAG Newsletter, February 1st, 2018.

FREIRE, Gabriela de Carvalho. "Distinções eyiguayegui”. Tese de doutorado, Programa de Pós-Graduação em Antropologia Social, Universidade de São Paulo, 2018.

GOW, Peter. "Lévi-Strauss' 'double twist' and controlled comparison: transformational relations between neighbouring societies”. Anthropology of This Century, London, n. 10, 2014.

GUIMARÃES, Antônio Sérgio. "A república de 1889: utopia de branco, medo de preto (a liberdade é negra; a igualdade, branca e a fraternidade, mestiça)”. Contemporânea, 2, 2011, p. 17-36.

INGLIS, David; ROBERTSON, Roland."From Republican Virtue to Global Imaginary: changing visions of the historian Polybius". History of the Human Sciences. v. 19, n. 1, 2006, p. 1-18.

KEESE, Lucas. "A esquiva do xondaro: movimento e ação política entre os Guarani Mbya”. Dissertação. Programa de Pós-Graduação em Antropologia Social. Universidade de São Paulo, 2017.

KELLY, José Antônio. "Perspectivismo multinatural como transformação estrutural”, Ilha, v.12, n.1, 2010, p.136-160.

- Sobre a antimestiçagem. Florianópolis, Cultura e Barbárie,

2016.

LÉVI-STRAUSS, Claude. Reciprocity and Hierarchy. American Anthropologist, vol. 46, no. 2. 1944a.

. "The Social and Psychological Aspects of Chieftainship in a Primitive tribe: The Nambikuara of Northwestern Mato Grosso" In COHEN, Ronald \& MIDDLETON, John (eds.), Comparative political systems: studies in the politics of pre-industrial societies. New York, Natural History Press, 1944b, p. $45-62$.

1976 [1949].

. As estruturas elementares do parentesco. São Paulo, EDUSP,

[1958].

. Antropologia estrutural. Rio de Janeiro, Tempo Brasileiro, 1975

[1962].

O pensamento selvagem. Campinas, Papirus Editora, 2008

. O homem nu. São Paulo: Cosac \& Naify, 2011 [1971].

. História de Lince. São Paulo: Companhia das Letras, 1991.

LIMA, Tânia Stolze. 2008. "Uma história do dois, do uno e do terceiro". In

CAIXETA DE QUEIRÓS, Ruben e NOBRE, Renarde Freire (orgs). Lévi-Strauss:

Leituras brasileiras. Belo Horizonte: Editora UFMG. p. 209-263. 
LOWIE, Robert."Political Organization of American Aborigenes”. In DU BOIS, C. (org.). Lowie's Selected Papers. University of California Press. 1960 [1948], p. 273-276.

MACEDO, Valéria. "Vetores porã e vai na cosmopolítica guarani". Revista Tellus, n.21, ano 11, Campo Grande, 2011, p. 25-52.

MACHADO, André Roberto de A. "As interpretações dos contemporâneos sobre as causas da Cabanagem e o papel do Parlamento." Revista de História, 175, 2016, p. 281-317.

MAQUIAVEL, N, O príncipe (1513). LCC Publicações Eletrônicas, Documento eletrônico. Disponível em:< http://www. dominiopublico. gov. br/download/texto/cvoooo52. pdf>. Acesso em: jul. 2018

MAQUIAVEL, N, Comentários Sobre a Primeira Década de Tito Lívio "Discorsi”, Editora UnB, Brasília, 1994.

MARTÍN, Carlos Andrés. “Aristóteles para economistas”. El Arco y la Lira. Tensiones y Debates, $4^{\circ}$, 2016, p. 57-64.

MAYBURY-LEWIS, David. A Sociedade Xavante. Rio de Janeiro, Francisco Alves Editora, 1984 [1967].

MERCADANTE, Paulo, A consciência conservadora no Brasil. Rio de Janeiro, Nova Fronteira, 1980.

MORGAN, Lewis Henry. Ancient Society. H. Holt, 1877.

MULGAN, R., "Machiavelli, Aristotle and Pocock - a Question of Evidence". New Zealand Journal of History, 15 (1), 1981, p. 61-67.

.“Aristotelian Social Democrat?”. Ethics, 111 (1), 2000, 79-101.

MUNANGA, Kabengelê. Rediscutindo a mestiçagem no Brasil: identidade nacional versus identidade negra. Rio de Janeiro, Vozes, 1999.

NUNES, Eduardo Soares. 2014. O constrangimento da forma: transformação e (anti-)hibridez entre os Karajá de Buridina (Aruanã-GO). Revista de Antropologia, v. 57, n. 1, p. 303-345.

PERRONE-MOISÉS, Beatriz. "Notas sobre uma certa confederação guianense”. Colóquio Guiana Ameríndia, História e Etnologia. Belém do Pará. NHIIUSP/EREACNRS/MPEG.Outubro/Novembro, 2006.

. "Bons chefes, maus chefes, chefões: excertos de filosofia política ameríndia”, Revista de Antropologia, v.54, n.2, 2011, p. 857-883.

Festa e Guerra. Tese de livre docência, Departamento de Antropologia Social, Universidade de São Paulo, 2015.

PERRONE-MOISÉS, Beatriz e SZTUTMAN, Renato. "Dualismo em perpétuo desequilíbrio feito política: desafios ameríndios", Novos modelos comparativos: antropologia simétrica e sociologia pós-social, 33a. Reunião da ANPOCS, Caxambu, 2009.

.Notícias de uma certa confederação tamoio". Mana, v. 16, n. 2, Rio de Janeiro, 2010, p. 401-443. 
PINTO, José Vandério Cirqueira. Geograficidade libertária em Élisée Reclus: Contribuição heterodoxa à história da Geografia. Tese de doutorado, Geografia, Universidade Estadual Paulista, 2015.

POCOCK, John G. A. The Machiavellian Moment: Florentine Political Thought and the Atlantic Republican Tradition. Princeton:,Princenton University Press, 1975 .

Cambridge University Press, 2008.

Political Thought and History: Essays on Theory and Method. PROUDHON, Pierre-Joseph. La guerre et la paix; recherches sur le principe et la constitution du droit des gens. Paris, E. Dentu, 1861.

[1863].

Do princípio federativo. São Paulo: Editora Imaginário, 2001

.Proudhon. Coleção Grandes Cientistas Sociais. RESENDE e PAS-

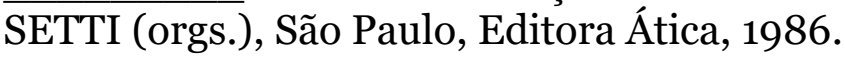

RECLUS, Élisée, O Brasil e a Colonização, São Paulo, Editora Imaginário, 2011 [1862].

RIVERA, Silvia in MAXWELL, Barry \& CRAIB, Raymond (orgs). No Gods, No Masters, No Peripheries: Global Anarchisms. Oakland, PM Press, 2015.

SCHWARCZ, Lilia Moritz. "Usos e abusos da mestiçagem e da raça no Brasil: uma história das teorias raciais em finais do século XIX". Afro-Ásia. Salvador, n.18, 1996, p.p. 77-101.

SKODA, Adriano. A recepção de Hélice Reclus no Brasil: uma narrativa científica, Dissertação de mestrado, Geografia Humana, Universidade de São Paulo, 2016.

SZTUTMAN, Renato. "O profeta e o principal: a ação política ameríndia e seus personagens". Tese de doutorado, Antropologia Social, Universidade de São Paulo. 2005.

.Introdução: Pensar com Pierre Clastres ou da atualidade do contra-Estado”. Revista de Antropologia. São Paulo, v.54, n.2, 2011., p. 557-576.

. "Metamorfoses do Contra-Estado - Pierre Clastres e as Políticas Ameríndias". Ponto Urbe, n. 13, São Paulo, 2013.

VIANNA, Fernando. A bola, os "brancos" e as toras: futebol para índios xavantes. São Paulo, Dissertação de mestrado, Antropologia Social, Universidade de São Paulo, 2001.

VIANA, Pedro Alex Rodrigues. "Os Hiper-guerreiros: guerra, comércio e predação entre os Ashaninka”. Dissertação de mestrado, Instituto de Ciências Humanas e Filosofia, Universidade Federal Fluminense, 2013.

. "O mundo em transformação: cosmopolítica e desenvolvimento entre os Asháninka do rio Ene, Selva Central do Peru", Revista Ñanduty 5.6, 2017, p. 80-102

VIVEIROS DE CASTRO, Eduardo. 2015 [2009]. Metafísicas canibais: elementos 
para uma antropologia pós-estrutural, São Paulo: Cosac Naify.

ZEA, Evelyn Schuler. "Por caminhos laterais: modos de relação entre os Waiwai no Norte Amazônico". Antropologia em Primeira Mão, Universidade Federal de Santa Catarina, Florianópolis, v. 119, p. 5-21, 2010. 